\title{
Direct and residual effects of zinc on zinc-efficient and zinc-inefficient rice genotypes grown under low-zinc-content submerged acidic conditions
}

\begin{abstract}
Zinc $(\mathrm{Zn})$ deficiency has been identified as a major cause of poor yield in rice. Flooding and submergence bring about a decline in available $\mathrm{Zn}$ due to $\mathrm{pH}$ changes and the formation of insoluble Zn compounds. A field experiment (undisturbed randomized complete block design with three replications) was conducted in farmersôfields of Kedah state during 2008 and 2009 to determine the direct and residual response of $\mathrm{Zn}$ on rice genotypes at the rates of 0 and $15 \mathrm{~kg} \mathrm{Zn}$ hai 1 in low-Zn-content acidic submerged soil. The genotypes differed significantly in grain yield and its components. Single application of $\mathrm{Zn}$ significantly increased the growth and yield of the crop for two seasons. Based on the grain yield efficiency index, the most Zn-efficient genotypes were MR 106 and Seri Malaysia Dua. Two genotypes, MR 220 and MR 219, were moderately efficient, but MR 211 and Bahagia were classified as inefficient.
\end{abstract}

Keyword: Acid soil; Flooded; Residual Zn; Rice; Zn efficiency 